\title{
A Rare Occurance of Eosinophilic Ascites in Pregnancy
}

Arvind K Mathur ${ }^{1 *}$ and Gaurav Singhvi ${ }^{2}$

${ }^{1}$ Hemet Valley Medical Center, Western University of Health Sciences, Pomona, California, USA

${ }^{2}$ David Geffen UCLA School of Medicine, Los Angeles, California, USA

*Corresponding author:Arvind K Mathur, Hemet Valley Medical Center, Western University of Health Sciences, Pomona, California 91766, USA, Tel: 909-206-8185; Email: amathur@llu.edu

Received Date: October 24, 2017; Accepted Date: November 13, 2017; Published Date: November 20, 2017

Copyright: () 2017 Mathur AK, et al. This is an open-access article distributed under the terms of the Creative Commons Attribution License, which permits unrestricted use, distribution, and reproduction in any medium, provided the original author and source are credited.

\begin{abstract}
Eosinophilic ascites (EA) is an exceedingly rare disorder of unknown etiology characterized by elevated number of eosinophils in ascitic fluid. EA is the rarest subtype of eosinophilic gastroenteritis and is characterized by infiltration of eosinophils in serosal layer of gastrointestinal tract. EA usually occurs in female patients, is mostly associated with atopic disorders, and is easily treatable with corticosteroids. Association with pregnancy is rare and why it occurs in pregnant females is unknown. We report a case of EA which to our knowledge is the first case of idiopathic EA in a pregnant patient and was easily treatable with corticosteroids without adverse effect on fetus.
\end{abstract}

Keywords: Etiology; Gastroenteritis; Corticosteroids; Diagnostic abilities

\section{Introduction}

Eosinophilic gastroenteritis, (EG) first described by Kaijser in 1937, is a rare disorder of unknown etiology characterized by eosinophilic infiltration of one or more layers of gastrointestinal wall. Klien et al. classify eosinophilic ascites (EA) as the rarest subtype of eosinophilic gastroenteritis, characterized by elevated number of eosinophils in ascitic fluid. Around 300 cases of EG and 15 cases of EA have been reported in literature, mostly in last decade due to increased diagnostic abilities. We report a case of EA which to our knowledge is the first case of idiopathic EA in a pregnant patient.

\section{Case Presentation}

A 29-year-old Hispanic female, gravida 5/para 4, 19 weeks pregnant, with a history of gestational diabetes and asthma, was admitted to our institution for nausea, vomiting, diffuse abdominal pain and loose non-bloody stools of 3-day duration. Nausea and vomiting were insidious in onset and preceded abdominal pain by one day. Vomitus was non-bilious, non-bloody and consisted of food she ate. Abdominal pain was diffuse, dull aching, and intermittent with no exacerbating or relieving factors. Vital signs in the emergency room were normal. Physical examination was remarkable for gravid uterus, generalized abdominal tenderness and shifting dullness. An ultrasound of the abdomen revealed hepatosplenomegaly, dilated portal vein and diffuse ascites (Figures 1 and 2).

Paracentesis removed $1250 \mathrm{ml}$ sero-sanguinous fluid (RBCs $10000 / \mathrm{mm}^{3}$, WBCs $6908 / \mathrm{mm}^{3}$, eosinophils $89 \%$, glucose $61 \mathrm{mg} / \mathrm{dL}$, protein $40280 \mathrm{mg} / \mathrm{L}$, gram stain and culture negative). Complete blood count (CBC) showed WBC $13.8 \times 10^{3} / \mathrm{mm}^{3}$ (neutrophils $53 \%$, lymphocytes $15 \%$, monocytes $3 \%$, eosinophils $29 \%$, basophils $0.2 \%$ ).

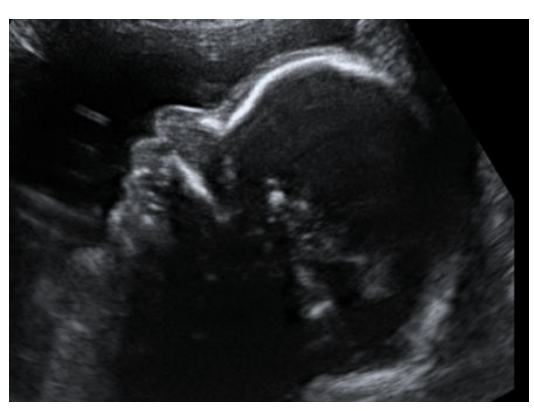

Figure 1: Fetus in patient.

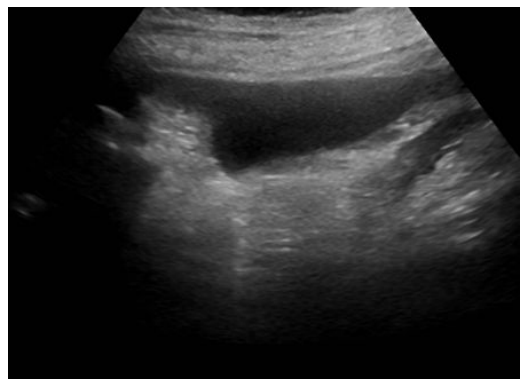

Figure 2: Peritoneal cavity of pregnant patient with ascites

Comprehensive metabolic profile, serum ceruloplasmin level and lipid profile were normal while hepatitis panel, serum anti-nuclear antibodies, smooth muscle antibody, stool ova and parasites and fecal leukocytes were negative. An esophagogastroduodenoscopy (EGD) showed esophagitis and gastritis without varices or portal hypertensive gastropathy (Figures 3-5). 


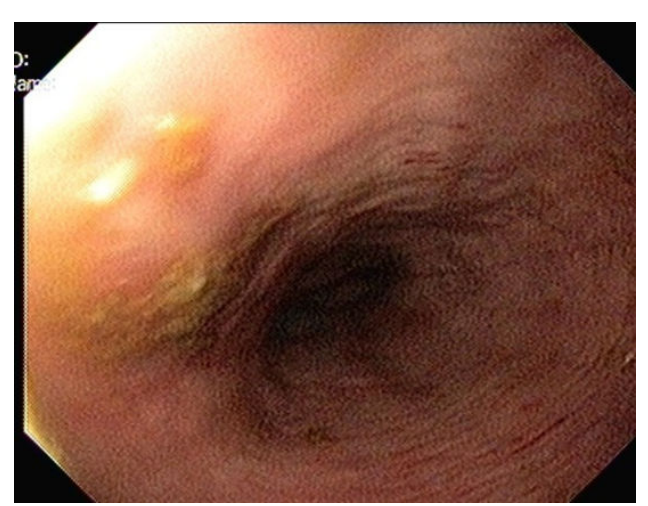

Figure 3: EGD view 1.

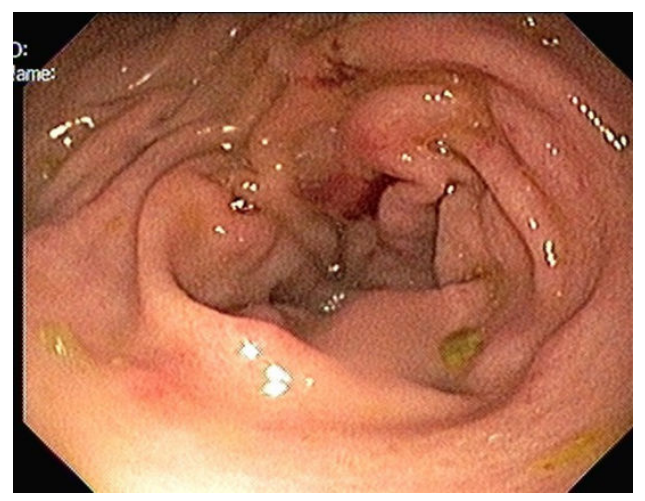

Figure 4: EGD view 2.

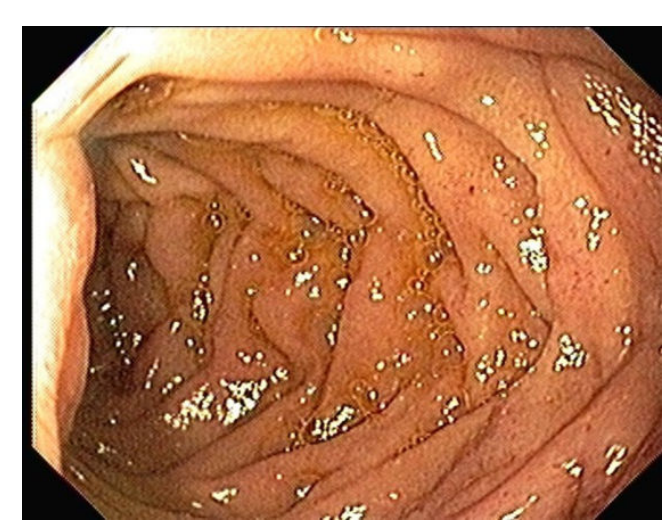

Figure 5: EGD view 3.

Esophageal biopsy showed benign squamous mucosa containing numerous infiltrating eosinophils ( $>50 / \mathrm{hpf}$ ) (Figure 6).

Stomach biopsy revealed benign fundic and antral type mucosa with focal eosinophilic infiltrates in serous layer (>50/hpf) (Figure 7).

A diagnosis of eosinophilic ascites was made. Prednisone $20 \mathrm{mg}$ oral daily was started. Her symptoms improved rapidly and patient was discharged 2 days later. Unfortunately, the patient stopped steroids 6 weeks after discharge due to lack of insurance coverage.

After one week of stopping steroids, her symptoms recurred but with milder severity. A repeat ultrasound of the abdomen during follow-up showed improved organomegaly and ascites compared to previous exam.

She was restarted on prednisone $10 \mathrm{mg}$ oral daily. Follow-up at 3 months revealed complete resolution of her symptoms, ascites and organomegaly. Peripheral eosinophilia also resolved. Rest of the pregnancy was uneventful and she delivered a healthy full term infant.

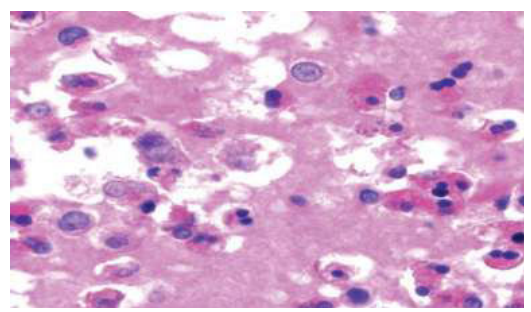

Figure 6: Microscopic image (Courtesy: cytojournal.com).

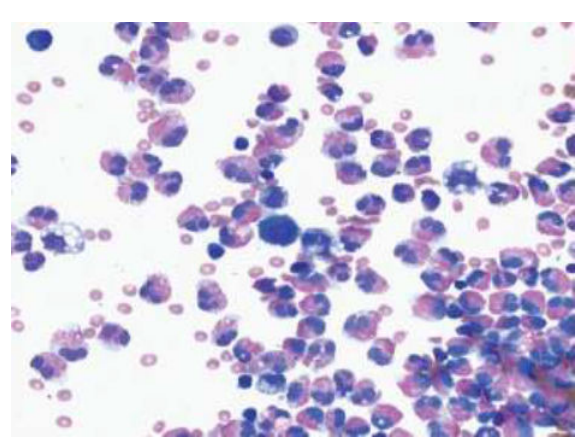

Figure 7: Microscopic image (Courtesy: cytojournal.com).

\section{Discussion}

Eosinophilic gastroenteritis (EG) is an uncommon disorder characterized by eosinophilic infiltration of gut wall and peripheral blood eosinophilia in the absence of a known cause for the latter, such as parasitic infestation, malignancy or allergy, etc. It can present with a wide spectrum of symptoms, may affect essentially any part and any or all layers of the gastrointestinal tract. Different subtypes of EG derive their nomenclature depending on the layer of the gut wall involved. Klein was the first to describe subtypes of eosinophilic gastroenteritis based on the depth of tissues involved [1]. Whereas involvement of the mucosal layer is the most common subtype (Table 1), eosinophilic ascites (EA) is probably the most unusual and rare presentation of EG that is generally associated with the serosal form of EGE. EA is seen in less than $10 \%$ of cases of EG [2,3]. Though most cases of EA are idiopathic, an association with other atopic or allergic diseases such as asthma or food allergy has occasionally been reported [4-6]. A few cases have been reported in children and also in post-partum women [7-12]. However, association of EG or EA by childbirth or pregnancy has not been reported in literature. Ours is the first case of eosinophilic 
ascites that developed during pregnancy and responded well to steroids.

\begin{tabular}{|l|l|}
\hline Subtype & Characteristic \\
\hline Mucosal form & $\begin{array}{l}\text { most frequent form [6], involves mucosa and submucosa, but not the muscularis propria [1]; symptoms are related to dysfunction of } \\
\text { the mucosa with malabsorption and possible protein-losing enteropathy (diarrhea, steatorrhea, weight loss, hypoalbuminemia, } \\
\text { peripheral edema, occult fecal bleeding, iron-deficiency anemia); more frequently associated with a history of allergy or high total } \\
\text { IgE levels (atopy) [13] }\end{array}$ \\
\hline Muscular form & $\begin{array}{l}\text { involves the muscularis propria; consequent thickening of the wall results in sub-occlusive signs (colicky pain, nausea, and/or } \\
\text { vomiting) }\end{array}$ \\
\hline Serosal form & $\begin{array}{l}\text { isolated or associated involvement of the serosa; observed in less than 10\% of cases; eosinophilic ascites is pathognomic; typical } \\
\text { in women of childbearing age. }\end{array}$ \\
\hline
\end{tabular}

Table 1: Classification of eosinophilic gastroenteritis.

\section{Pathophysiology}

Long thought as an idiopathic disorder, EG (and it's all subtypes) is now believed to occur as a result of a complex interaction of genetic, environmental and immune systems [14-16]. A defective mucosal barrier allows environmental allergens to pass through, activating both humoral and cell-dependent immune response [2,6,17]. Activated lymphocytes and mast cells secrete interleukin-5 (IL-5), a cytokine which attracts and activates eosinophils [18]. Once activated, eosinophils recruit themselves in an autocrine manner, secreting several pro-inflammatory cytokines such as transforming growth factor, granulocyte-macrophage colony stimulating factor, IL-3 and IL-5 $[18,19]$. This theory is further supported by the observation that mast cell stabilizer sodium cromoglycate have been effective in some cases of EG [20-22]. This autocrine cycle continues and IL-5 and eosinophils together help potentiate immune response. Desreuxmaux et al. found an increase in total serum IgE levels with RAST positive for food allergens, and an increased number of lymphocytes and eosinophils in patients with EA as compared to normal population [23]. Paracentesis in these patients shows a sterile exudative effusion containing as many as $95 \%$ eosinophils [24,25].

\section{Symptomatology}

The symptomatology of EG is a reflection of the anatomical and histological site involved. Antrum and proximal small intestine are the commonest sites involved [4,26-28]. Patients most commonly present with abdominal pain (70-100\%), diarrhea (45-70\%), nausea and vomiting (30-50\%), and recurrent ascites (10-20\%) [4]. EA can be distinguished from other disorders causing ascites by higher peripheral eosinophilia but excellent clinical response to steroids $[2,29,30]$.

\section{Diagnosis}

Diagnostic criteria for EA include: a) presence of gastrointestinal signs and symptoms (as described above), b) absence of other known causes of eosinophilia like malignancy, parasitic and fungal infections, autoimmune diseases, drug reactions, cholesterol embolism and hyperimmunoglobulin syndrome, c) eosinophilic infiltration in serosal layer of gut wall and ascitic fluid [2,31,32]. Diagnosis is made by analysis of ascitic fluid, $\mathrm{CBC}$ and EGD with biopsy. There is no literature on how many eosinophils should be seen in ascitic fluid to make the diagnosis but usually 10 eosinophils per high power field is cutoff in our practice. Peripheral eosinophilia is seen in 50\%-90\% patients but is not essential for diagnosis [4,33,34]. Magnitude of peripheral eosinophilia is directly proportional to the severity of symptomatology $[5,35]$. Around $80 \%$ of the cases are associated with atopic disorders and $16 \%$ have an affected immediate family member [36]. Although EG is more common in males, EA has predominantly been diagnosed in females [37].

\section{Treatment}

Corticosteroids are the mainstay of therapy and the response is excellent [38]. There are no consensus guidelines for dose and duration of steroid treatment. Patients can usually be started on $40 \mathrm{mg}$ of oral prednisone and gradually tapered off over two weeks $[6,31,39,40]$. Alternative therapy with a mast cell stabilizer (sodium cromoglycate) has been tried successfully in several patients with the mucosal form but has not been well studied in patients with the serosal form. PérezMillán et al. reported complete resolution of EA in a young patient after sodium cromoglycate treatment with no recurrence at one year [22]. It is yet to be determined whether other alternative measures including ketotifen [41-43], montelukast [39,44,45] and elimination diet [46-49] are useful in any form of EG at all. Only three cases of eosinophilic ascites have been reported in literature which improved without medical therapy [50]. General consensus is that prognosis is excellent $[21,51]$ but the disease can easily progress into a chronic or relapsing-remitting form [52].

\section{Conclusion}

Eosinophilic ascites in our patient appeared during pregnancy and did not recur after delivery. It is unclear what could have triggered this idiopathic incidence. A fetal antigen or an altered immune status during pregnancy in this patient with a history of an atopic disorder (asthma) may be postulated. Though our patient needed longer than recommended duration of steroids, her disease showed excellent response to therapy even though that incomplete treatment with steroids led to a relapse of the disease in her case. There were no adverse effects on pregnancy or fetus. In the future, it would be interesting to know if pregnancy alters the course of EA in a patient with a previous diagnosis of EA or EG or atopic disorders.

\section{References}

1. Klein NC, Hargrove RL, Sleisenger MH, Jeffries GH (1970) Eosinophilic gastroenteritis. Medicine (Baltimore) 49: 299-319. 
2. Fenoglio LM, Benedetti V, Rossi C, Anania A, Wulhfard K, et al. (2003) Eosinophilic gastroenteritis with ascites: a case report and review of the literature. Dig Dis Sci 48: 1013-1020.

3. Pozzato P, Salerno S, Cancellieri A, Gallone AA (2012) Eosinophilic ascites: A case report. Italian Journal of Medicine 6: 1-3.

4. Talley NJ, Shorter RG, Phillips SF, Zinsmeister AR (1990) Eosinophilic gastroenteritis: A clinicopathological study of patients with disease of the mucosa, muscle layer, and subserosal tissues. Gut 31: 54-58.

5. Naylor AR (1990) Eosinophilic gastroenteritis. Scott Med J 35: 163-165.

6. Lee CM, Changchien CS, Chen PC, Lin DY, Sheen IS, et al. (1993) Eosinophilic gastroenteritis: 10 years' experience. Am J Gastroenterol 88: 70-74.

7. Barabino AV, Castellano E, Gandullia P, Torrente F, Guida A, et al. (2003) Chronic eosinophilic ascites in a very young child. Eur J Pediatr 162: 666-668.

8. Steffen RM, Wyllie R, Petras RE, Caulfield ME, Michener WM, et al. (1991) The spectrum of eosinophilic gastroenteritis. Report of six pediatric cases and review of the literature. Clin Pediatr (Phila) 30: 404-411.

9. Whitington PF, Whitington GL (1988) Eosinophilic gastroenteropathy in childhood. J Pediatr Gastroenterol Nutr 7: 379-385.

10. Teng $\mathrm{X}, \mathrm{Xu} \mathrm{L}, \mathrm{Wu}$ J, Sun M, Guo J, et al. (2013) Clinical and morphological features of serosal form of eosinophilic gastroenteritis in a retrospective study of 10 children. Fetal Pediatr Pathol 32: 276-283.

11. Milï̈ S, Poropat G, Malï̈ D, Stimac D (2012) A case of postpartum eosinophilic gastroenteritis and review of the literature. Dig Dis 30: 232-235.

12. Hepburn IS, Sridhar S, Schade RR (2010) Eosinophilic ascites, an unusual presentation of eosinophilic gastroenteritis: A case report and review. World J Gastrointest Pathophysio 1: 166-170.

13. [No authors listed] (1993) Case records of the Massachusetts General Hospital. Weekly clinicopathological exercises. Case 30-1993. A 59-yearold woman with abdominal pain and an abnormal CT scan. N Engl J Med 329: 343-349.

14. Alfadda AA, Storr MA, Shaffer EA (2011) Eosinophilic colitis: an update on pathophysiology and treatment. Br Med Bull 100: 59-72.

15. Alfadda AA, Storr MA, Shaffer EA (2012) Eosinophilic gastroenteritis: Two case reports. Ultrasound 20: 224-227.

16. Lucendo AJ (2010) Eosinophilic diseases of the gastrointestinal tract. Scand J Gastroenterol 45: 1013-1021.

17. Bischoff SC (2010) Food allergy and eosinophilic gastroenteritis and colitis. Curr Opin Allergy Clin Immunol 10: 238-245

18. Bischoff SC (1996) 4 Mucosal allergy: Role of mast cells and eosinophil granulocytes in the gut. Baillieres Clin Gastroenterol 10: 443-459.

19. Takafuji S, Bischoff SC, De Weck AL, Dahinden CA (1991) IL-3 and IL-5 prime normal human eosinophils to produce leukotriene $\mathrm{C} 4$ in response to soluble agonists. J Immunol 147: 3855-3861.

20. Khan S, Orenstein SR (2002) Eosinophilic gastroenteritis: Epidemiology, diagnosis and management. Paediatr Drugs 4: 563-570.

21. Rafiq AS, Thomas PP, Erick PR, Boris HR (2009) Unusual presentations of eosinophilic gastroenteritis: Case series and review of literature. World J Gastroenterol 15: 2156-2161.

22. Pérez-Millán A, Martín-Lorente JL, López-Morante A, Yuguero L, SáezRoyuela F (1997) Subserosal eosinophilic gastroenteritis treated efficaciously with sodium cromoglycate. Dig Dis Sci 42: 342-344.

23. Desreumaux P, Bloget F, Seguy D, Capron M, Cortot A, et al. (1996) Interleukin 3, granulocyte-macrophage colony-stimulating factor, and interleukin 5 in eosinophilic gastroenteritis. Gastroenterology 110: 768-774.

24. Daneshjoo R, J Talley N (2002) Eosinophilic gastroenteritis. Curr Gastroenterol Rep 4: 366-372.

25. Le Connie D, Nguyen H (2004) Eosinophilic gastroenteritis, ascites, and pancreatitis: A case report and review of the literature. South Med J 97: 905-906.
26. Wiesner W, Kocher T, Heim M, Bongartz G (2002) Findings in eosinophilic enterocolitis with predominantly serosal and muscular bowel wall infiltration. JBR-BTR 85: 4-6.

27. Marco-Doménech SF, Gil-Sánchez S, Jornet-Fayos J, Ambit-Capdevila S, Gonzalez-Añón M (1998) Eosinophilic gastroenteritis: Percutaneous biopsy under ultrasound guidance. Abdom Imaging 23: 286-2888.

28. MacCarty RL, Talley NJ (1990) Talley, Barium studies in diffuse eosinophilic gastroenteritis. Gastrointest Radiol 15: 183-187.

29. Setia N, Ghobrial P, Liron P (2010) Eosinophilic ascites due to severe eosinophilic ileitis. Cytojournal 7: 19.

30. Alzahrani MAA, Alqahtani AM, Nemri SA, Alshehri SN (2012) An unusual presentation of eosinophilic gastroenteritis: Case report and literature review. The Open Gastroenterology Journal 6: 31-33.

31. Yun MY, Cho YU, Park IU, Choi SK, Kim SJ (2007) Eosinophilic gastroenteritis presenting as small bowel obstruction: A case report and review of the literature. World J Gastroenterol 13: 1758-1760.

32. Hsu YQ, Lo CY (1998) A case of eosinophilic gastroenteritis. Hong Kong Med J 4: 226-228.

33. Lee M, Hodges WG, Huggins TL, Lee EL (1996) Eosinophilic gastroenteritis. South Med J 89: 189-194.

34. Santos L, Santos V, Faria L, Dias T (2011) Spontaneous remission of eosinophilic ascites in a young patient. Brasília Méd 48: 330-332.

35. Chandrasekar TS, Goenka MK, Lawrence R, Gokul BJ, Murugesh M, et al. (2012) An unusual case of ascites. Indian J Gastroenterol 31: 203-207.

36. Guajardo JR, Plotnick LM, Fende JM, Collins MH, Putnam PE, et al. (2002) Eosinophil-associated gastrointestinal disorders: A world-wideweb based registry. J Pediatr 141: 576-581.

37. Durieu I, Nove-Josserand R, Cathebras P, Durand DV, Rousset H, et al. (1992) [Eosinophilic ascites. 2 new case reports]. Rev Med Interne 13: 446-448.

38. Zhang L, Duan L, Ding S, Lu J, Jin Z, et al. (2011) Eosinophilic gastroenteritis: Clinical manifestations and morphological characteristics, a retrospective study of 42 patients. Scand J Gastroenterol 46: 1074-1080.

39. Lim DNF, Wilkins A, Horton LE, Ahmad I, Polito CL, et al. (2012) Eosinophilic gastrointestinal disorder in coeliac disease: A case report and review. Case Rep Gastrointest Med 2012: 124275.

40. Khan S (2005) Eosinophilic gastroenteritis. Best Pract Res Clin Gastroenterol 19: 177-198.

41. Lee SI, BK H, DH K, Yoo JT, Choi SH et al. (2011) A case of eosinophilic gastroenteritis diagnosed by repeated abdominal pain with eosinophilic ascites and cystitis. Kosin Medical Journal 26: 191-195.

42. Suzuki J, Kawasaki Y, Nozawa R, Isome M, Suzuki S (2003) Oral disodium cromoglycate and ketotifen for a patient with eosinophilic gastroenteritis, food allergy and protein-losing enteropathy. Asian Pac J Allergy Immunol 21: 193-197.

43. Melamed I, Feanny SJ, Sherman PM, Roifman CM (1991) Benefit of ketotifen in patients with eosinophilic gastroenteritis. Am J Med 90: 310-314.

44. Neustrom MR, Friesen C (1999) Treatment of eosinophilic gastroenteritis with montelukast. J Allergy Clin Immunol 104: 506.

45. Schwartz DA, Pardi DS, Murray JA (2001) Use of montelukast as steroidsparing agent for recurrent eosinophilic gastroenteritis. Dig Dis Sci 46: 1787-1790.

46. Miyamoto T, Shibata T, Matsuura S, Kagesawa M, Ishizawa Y, et al. (1996) Eosinophilic gastroenteritis with ileus and ascites. Intern Med 35: 779-782.

47. Kagalwalla AF, Sentongo TA, Ritz S, Hess T, Nelson SP, et al. (2006) Effect of six-food elimination diet on clinical and histologic outcomes in eosinophilic esophagitis. Clin Gastroenterol Hepatol 4: 1097-1102.

48. Pfaffenbach B, Adamek RJ, Bethke B, Stolte M, Wegener M (1996) Eosinophilic gastroenteritis in food allergy. Z Gastroenterol 34: 490-493.

49. Spergel JM, Andrews T, Brown-Whitehorn TF, Beausoleil JL, Liacouras CA (2005) Treatment of eosinophilic esophagitis with specific food elimination diet directed by a combination of skin prick and patch tests. Ann Allergy Asthma Immunol 95: 336-343. 
Citation: Mathur AK, Singhvi G (2017) A Rare Occurance of Eosinophilic Ascites in Pregnancy. Hepatol Pancreat Sci 1: 109. doi:10.4172/ 2573-4563.1000109

Page 5 of 5

50. Liao WH, Wei KL, Po-Yen-Lin, Wu CS (2012) A rare case of spontaneous resolution of eosinophilic ascites in a patient with primary eosinophilic gastroenteritis. Chang Gung Med J 35: 35435-35439.

51. Baig MA, Qadir A, Rasheed J (2006) A review of eosinophilic gastroenteritis. J Natl Med Assoc 98: 1616-1619.
52. Pineton de Chambrun G, Gonzalez F, Canva JY, Gonzalez S, Houssin L, et al. (2011) Natural history of eosinophilic gastroenteritis. Clin Gastroenterol Hepatol 9: 950-956. 